\title{
Ascertainment of Informative Alzheimer Disease Families from the IMAGE Project Registry for Genetic Linkage Analysis Studies
}

\author{
D. Gautrin, J. Nalbantoglu, G. Lacoste-Royal, M. Grenon, S. Gauthier, R. Bouchard, \\ J. Mathieu, Y. Robitaille, L.-P. Doyon, H. Bergman, A. Cholette, M. de Braekeleer, \\ G. Bouchard and D. Gauvreau
}

\begin{abstract}
Genetic linkage analysis requires the identification and documentation of large families with many affected members present, preferably in more than one generation. The IMAGE Project has been establishing a population-based Alzheimer disease (AD) registry in the Saguenay - Lac-Saint-Jean region of the Province of Quebec. The population of this region has a well-documented ancestry, with reliable genealogical records (since 1842) computerized by SOREP. We have recently begun to investigate the pedigrees of selected probands (definite, probable and possible) from the IMAGE registry in order to identify informative pedigrees for genetic linkage analysis. Interviews were carried out with close relatives of the probands (at least one informant per sibship) to identify secondary AD cases. The questionnaires used pertain to the accuracy of genealogical records, to family medical history and to a retrospective diagnosis of AD for people with cognitive deficits. By these means, we have documented a large extended pedigree in which a total of 15 individuals with cognitive deficits were ascertained over three generations. Of these cases, 7 are still living and there is autopsy confirmation in another one. Computer simulations using the program SIMLINK revealed that this is a potentially informative family for linkage analysis. Horizontal extension of the pedigree to second cousins of the proband is now being carried out. This will render the family IMAGE/l even more informative in genetic linkage analysis studies.
\end{abstract}

RÉSUMÉ: Indentification de familles informatives atteintes de la maladie d'Alzheimer à partir du registre du projet image pour des études génétiques de liaison Il est nécessaire d'identifier et de documenter de grandes familles incluant plusieurs membres atteints, de préférence sur plus d'une génération, pour procéder à des études de liaison. Le projet IMAGE est en train d'établir un registre de patients atteints de la maladie d'Alzheimer à partir de la population du Saguenay-Lac-St-Jean, une région de la province de Québec. Les origines ancestrales de cette population sont bien connues et SOREP possède des données généalogiques informatisées fiables sur cette population. Nous avons récemment commencé à investiguer les pedigrees de certains cas index (cas certains, probables et possibles) à partir du registre IMAGE, dans le but d'identifier les pedigrees susceptibles d'être informatifs pour l'analyse de liaison. Nous avons procédé à des entrevues avec les proches parents des cas index (au moins un informateur par fratrie) afin d'identifier les cas secondaires de maladie d'Alzheimer. Les questionnaires utilisés investiguent l'exactitude des données généalogiques, l'histoire médicale familiale et un diagnostic rétrospectif de maladie d'Alzheimer chez les individus manifestant un déficit cognitif. Nous avons ainsi identifié une famille étendue comptant un total de 15 individus, répartis sur trois générations, manifestant un déficit cognitif. Parmi ces cas, 7 sont encore vivants et nous possédons un rapport d'autopsie confirmant la présence de la maladie d'Alzheimer chez un autre cas. Une simulation par ordinateur au moyen du programme SIMLINK a montré que cette famille était potentiellement informative pour l'analyse de liaison. Nous procédons présentement à l'extension horizontale du pedigree, incluant les cousins(ines) au 2e degré du cas index, ce qui va rendre la famille IMAGE/1 encore plus informative pour les études de liaison.

Can. J. Neurol. Sci. 1989; 16: 468-472

While the etiology of Alzheimer disease (AD) is unknown, various hypotheses have been put forward to account for its development. Factors most often cited include transmissible agents, environmental toxins and genetic defects. Thus far, the risk factor most consistently identified, besides advanced age, is having an affected blood relative. ${ }^{1-6}$ However, the genetic basis

From the INRS-Santé, Pointe-Claire (DGaut, JN, GL-R, MG and DGauv), McGill Centre for Studies in Aging (SG), Hopital de l'Enfant-Jésus (RB), Hopital de Chicoutimi (JM and AC), Montreal Neurological Institute (YR), Hopital de Roberval (L-PD), Jewish General Hospital, Montreal (HB), and Université du Québec à Chicoutimi (MdeB and GB), Quebec

Reprint requests to: J. Nalbantoglu, INRS-Santé, 245 Hymus Blvd., Pointe Claire, PQ, Canada H9R 1G6 
of $A D$ remains to be elucidated: the mode of transmission of the disease is uncertain and the percentage of familial cases in the general population is not known.

One of the best ways of establishing the involvement of genetic factors in the etiology of a disease is to show an association or a linkage of specific genetic markers with the disease trait. Due to inherent problems in establishing a pre-mortem diagnosis and to the late onset of the disease, genetic analyses have so far proven difficult to perform with Alzheimer cases. As a consequence of the late manifestation of $A D$, parental samples are rarely available for analysis, and few affected individuals can be sampled, even within the same generation. Furthermore, a definite diagnosis in most cases can be established only at autopsy so that there may be up to a $10-15 \%$ error rate in the diagnosis of living affected individuals. ${ }^{7,8}$ Ascertainment of cases from earlier generations is rarely based on well-documented medical records but relies mainly on retrospective family history, with its ensuing uncertainties. Some of these problems can be circumvented by analysing extended, multigeneration pedigrees in which an autosomal dominant transmission is established and where the affected individuals have been well characterized in terms of the clinical course of the disease and their neuropsychological deficits, and in whom neuropathological confirmation of AD was obtained through autopsy. The probands we have identified through the IMAGE Project comply with these requirements. [IMAGE is an acronym for

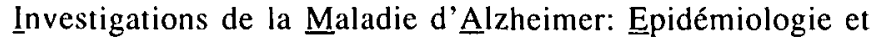
Génétique].

\section{The IMAGE Project and Genetic Studies}

The IMAGE Project was launched to provide a venue for a comprehensive study of the disease and to overcome the absence of an adequate animal or experimental model. Hence, a population-based registry of AD cases is currently being established in Saguenay - Lac-Saint-Jean (SLSJ), in the Province of Quebec (Figure 1), with the aim of screening as systematically as possible for all living $A D$ cases and of following them longitudinally. The field network operations of IMAGE have been described in detail elsewhere. 9,10 The objective of IMAGE is to accumulate and integrate data in a multidisciplinary fashion in order to gain better insight into the nature of AD. Ongoing projects within IMAGE are concerned with the clinical/neuropsychological/neuropathological correlations of $\mathrm{AD}$, the population genetics of the field of study, the identification of risk factors involved in the development of $\mathrm{AD}$, the socio-geographical distribution of cases over the area, the study of care-taking and case management in the field, and the molecular genetics of $A D$ in large extended families.

The IMAGE registry is unique of its kind and its strength lies in the possibility for its investigators to access a computerized data-base of all the parish registries of the region, currently dating back to 1842 , in collaboration with the SOREP consortium in Chicoutimi [SOREP stands for the Centre interuniversitaire de recherches sur les populations]. The SOREP computerized data-base contains data taken from church and civil records, censuses and various other sources (e.g. social, medical). The

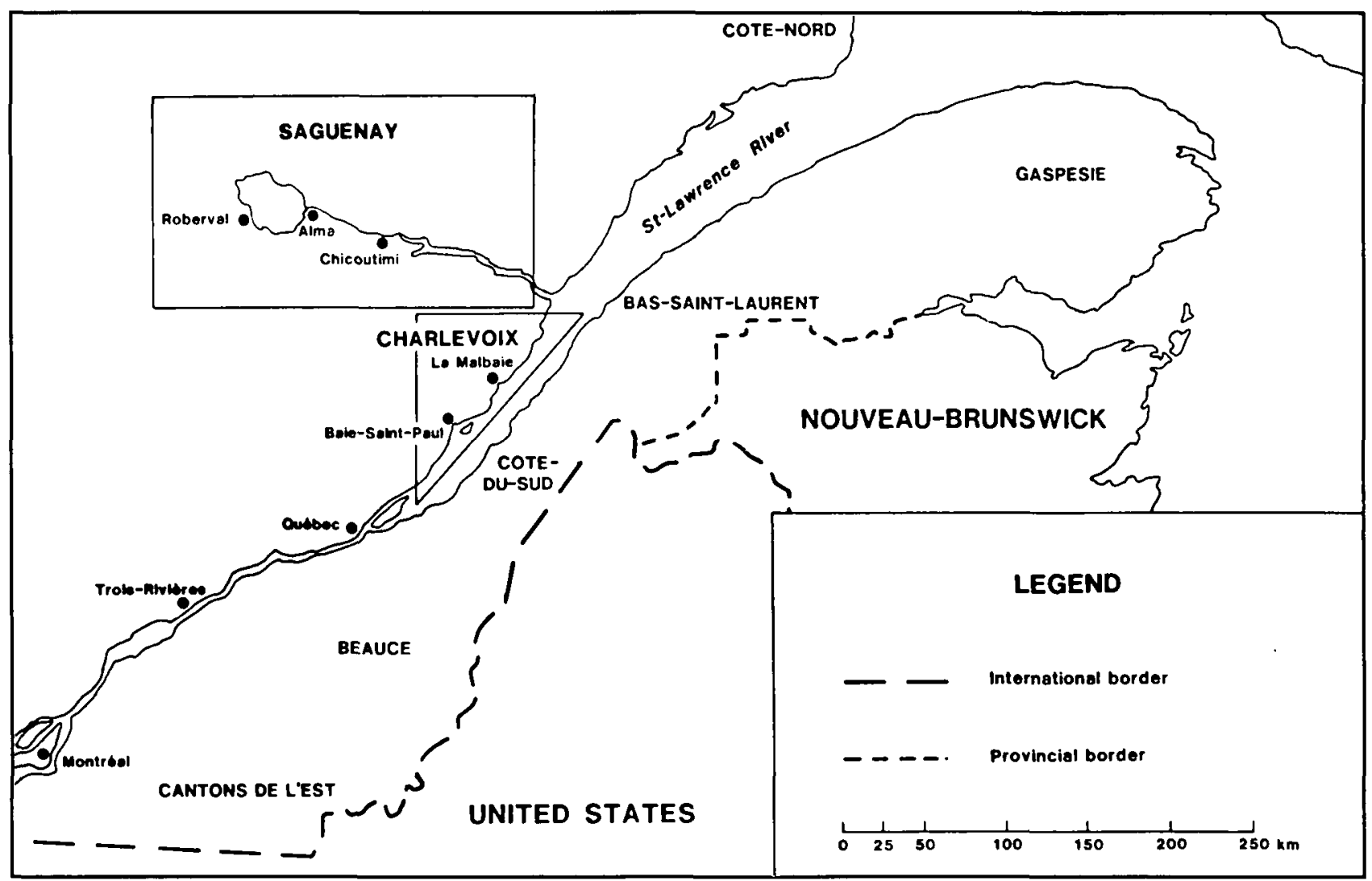

Figure 1-The Saguenay-Lac-Saint-Jean (SLSJ) territory, selected as field of study for the IMAGE Project. SLSJ is located north of the city of Quebec; it covers an area of approximately $22,500 \mathrm{~km}^{2}$, with a population of approximately 290.000 people. 
data, representing more than one million records, are divided between a central data-base and numerous sectorial files which have been linked through software that permits computerized reconstruction of families and genealogies. This data-base has information on place and date of birth, place and date of death, as well as residential and professional histories of the population. Anyone having spent his or her life in SLSJ appears on average 10 times in the SOREP records. This data-base will soon be extended into the Charlevoix area just south of SLSJ. Since it is estimated that $70-80 \%$ of the gene pool of SLSJ comes from Charlevoix, the IMAGE Project will be in a position to trace the ancestors of cases back to the seventeenth century. In practical terms, this ability to establish ascending and descending genealogies enables us to construct very wide pedigrees, e.g. up to second and third cousins of the AD probands.

Beyond the well-documented ancestry and the computerized genealogical records, the IMAGE Project population provides further important advantages. Within the region, large families with an average of 10 to 12 children/generation are the norm rather than the exception. This familial structure makes it easier to find affected living individuals in more than one generation, with the children of the older members of the sibships being approximately the same age as the younger members. Furthermore, large families have closely spaced siblings and additional family members might also be diagnosed as having AD during a short period of time (2 to 5 years).

The whole region of SLSJ was mostly populated from immigrants coming from Charlevoix; indeed, between 1838 and 1911 , some $75 \%$ of the immigrants came from that region. Thus, even if AD turns out to be a heterogeneous disease, one could expect to find "pockets" of homogeneity in terms of the genetic background of the IMAGE cases, that is, familial AD patients with the same genetic defect even in relatives more distant than the second degree. A probable "founder effect" for AD has been described in the descendants of the Volga Germans. ${ }^{11}$ A similar founder effect in SLSJ would facilitate linkage studies, allowing the work to be carried out from a much larger familial base.

\section{Investigation of Family Medical History}

We have recently begun to investigate the pedigrees of selected probands (definite, probable and possible) from the IMAGE registry in order to identify informative pedigrees for genetic linkage analysis. Two or more of the following criteria were applied, in combination, in the choice of families to be evaluated: 1) affected subjects with large sibships; 2) one or more probable AD cases (based on NINCDS-ADRDA criteria ${ }^{12}$ ); 3) neuropathological confirmation ${ }^{13}$ (also Ball, personal communication) on at least one case; 4) probable cases in two generations; 5) numerous first, second or third degree relatives having reached the age of risk. Most of the families we have investigated so far have fulfilled at least three of the above criteria.

Interviews were carried out with close relatives of the probands to identify secondary cases of AD. For each proband, one sibling and one member of each first cousin sibship were interviewed. In addition, any nephews or nieces who had reached the age of risk for $A D$ were also investigated. Each informant was asked to provide information about all his/her first degree relatives (parents and siblings and, if necessary, about unmarried aunts and uncles).

In the first questionnaire administered, the informants were asked to verify the pedigree structure of their own sibship and to supply information concerning missing individuals. Although all the persons who have resided in the SLSJ region should be entered at least once in the SOREP genealogical registry, it is conceivable that some relatives of $\mathrm{AD}$ probands might have spent their entire lives outside the region. Thus, we were able to confirm and complete the pedigree structure obtained from the genealogical records of SOREP.

The second questionnaire pertaining to the family medical history was derived from a questionnaire developed and validated by Breitner. ${ }^{14}$ At this stage of the project we were mainly interested in the presence of memory loss, dementia, or AD in the relatives of the proband. If, through this questionnaire, a relative was identified as having cognitive deficits, the caregiver or the best possible informant was identified for this individual. If the suspected dementia case was not in the IMAGE registry, either the case and/or the caregiver was asked permission to undertake the IMAGE registry diagnostic assessment protocol.

If the suspected dementia case was deceased, the person who best knew the deceased near the end of his/her life was administered a questionnaire to establish a retrospective diagnosis of $\mathrm{AD}$. This questionnaire, based on clinical experience, is divided into two sections: the first one seeks to identify exclusion criteria, while the second one concerns the presence of characteristic cognitive and functional impairments and their rate of progression. The questions in the first section pertain to causes of

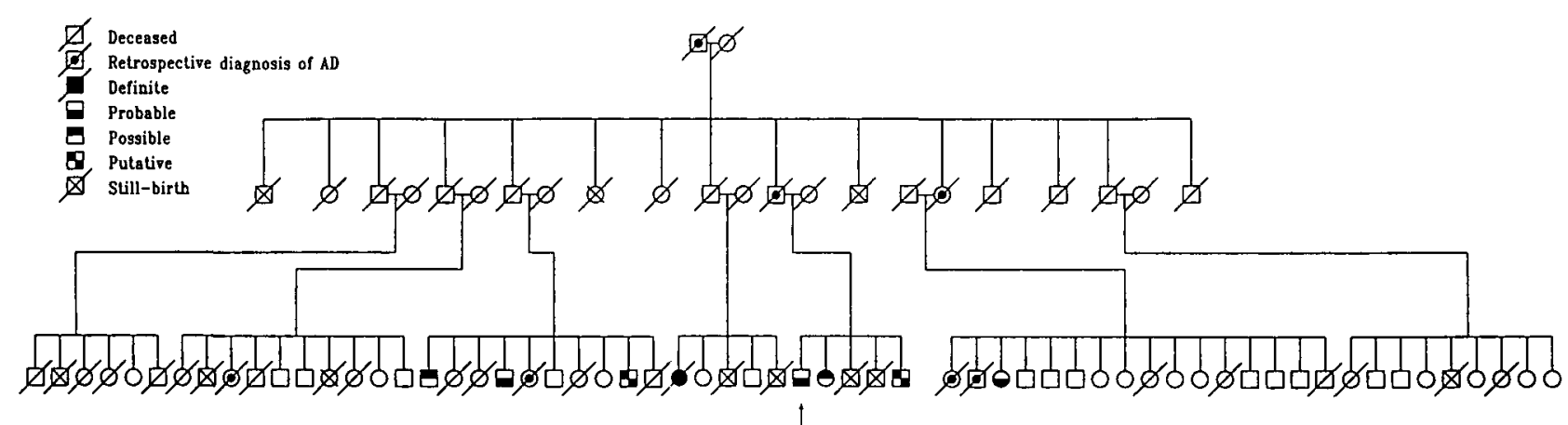

Figure 2 -Pedigree structure of the AD family IMAGE/l. Proband is identified by an arrow. 
Table 1: Simulation Analysis to Estimate the Power of Demonstrating Linkage with Pedigree IMAGE/1 using a Di-allelic Marker Locus (0.71, 0.29)

\begin{tabular}{ccc}
\hline \hline True recombination fraction & \multicolumn{2}{c}{$\begin{array}{c}\text { Estimated mean and } \\
\text { maximum lod scores }\end{array}$} \\
\hline \multirow{2}{*}{.000} & MEAN & 1.437 \\
& SE & .055 \\
& MAX & 6.525 \\
.050 & MEAN & 1.089 \\
& SE & .043 \\
& MAX & 5.945 \\
.100 & MEAN & .763 \\
& SE & .034 \\
& MAX & 5.445 \\
.150 & MEAN & .601 \\
& SE & .028 \\
& MAX & 5.355 \\
.200 & MEAN & .447 \\
& SE & .022 \\
& MAX & 4.999 \\
\hline
\end{tabular}

Simulation was performed with the SIMLINK program. 15 One thousand replications of the pedigree shown in Figure 2 were analyzed.

dementia other than AD (e.g. stroke, severe head injury, psychiatric diseases, other neurologic diseases, alcoholism, and drug abuse). In the second part, questions bear upon the presence of memory, language and orientation problems, as well as the extent of difficulty in performing the activities of daily living. The answers to this questionnaire were evaluated by a neurologist who then rendered a diagnosis of either probable AD, dementia of other cause, or absence of dementia.

To date we have completed the evaluation of six extended pedigrees. For all the families, we were able to contact at least one informant, per sibship, who was still residing in SLSJ. When required, we were also able to verify the presence of suspected dementia in an individual with additional informants. Although the information we had initially on some families suggested that they might provide interesting material for linkage analysis studies, full ascertainment in a short period of time allowed us to show that these were families with a low informative potential and that they need not be a priority. Only a set-up such as the one provided by the IMAGE-SOREP association (rapid genealogical reconstruction, families mostly confined to a small geographical territory, etc.) allows such a quick and rapid evaluation.

\section{Identification of an Informative Pedigree}

The following criteria were used for the selection of potential families for participation in genetic linkage studies: 1) clear evidence of autosomal dominant transmission; 2) clinical diagnosis of probable AD; 3) at least one neuropathological confirmation per family; 4) the presence of several affected and unaffected individuals available for genotyping and who are willing to cooperate.

Of the six documented pedigrees, we have identified one large family (IMAGE/I) which fulfills the criteria set above. The proband is a probable $A D$ case in a family presenting with a history of cognitive deficits in his father and in his sister. Investigation of the family medical history has shown that a total of 15 individuals over three generations have or have had cognitive deficits (Figure 2). In the generation of the proband, there is one definite, three probable and two possible cases, as well as two putative cases who have yet to see a neurologist. In addition, four of the deceased cousins of the proband were diagnosed as $\mathrm{AD}$ by the retrospective diagnosis questionnaire. To date, of the 37 individuals in the generation of the proband surviving

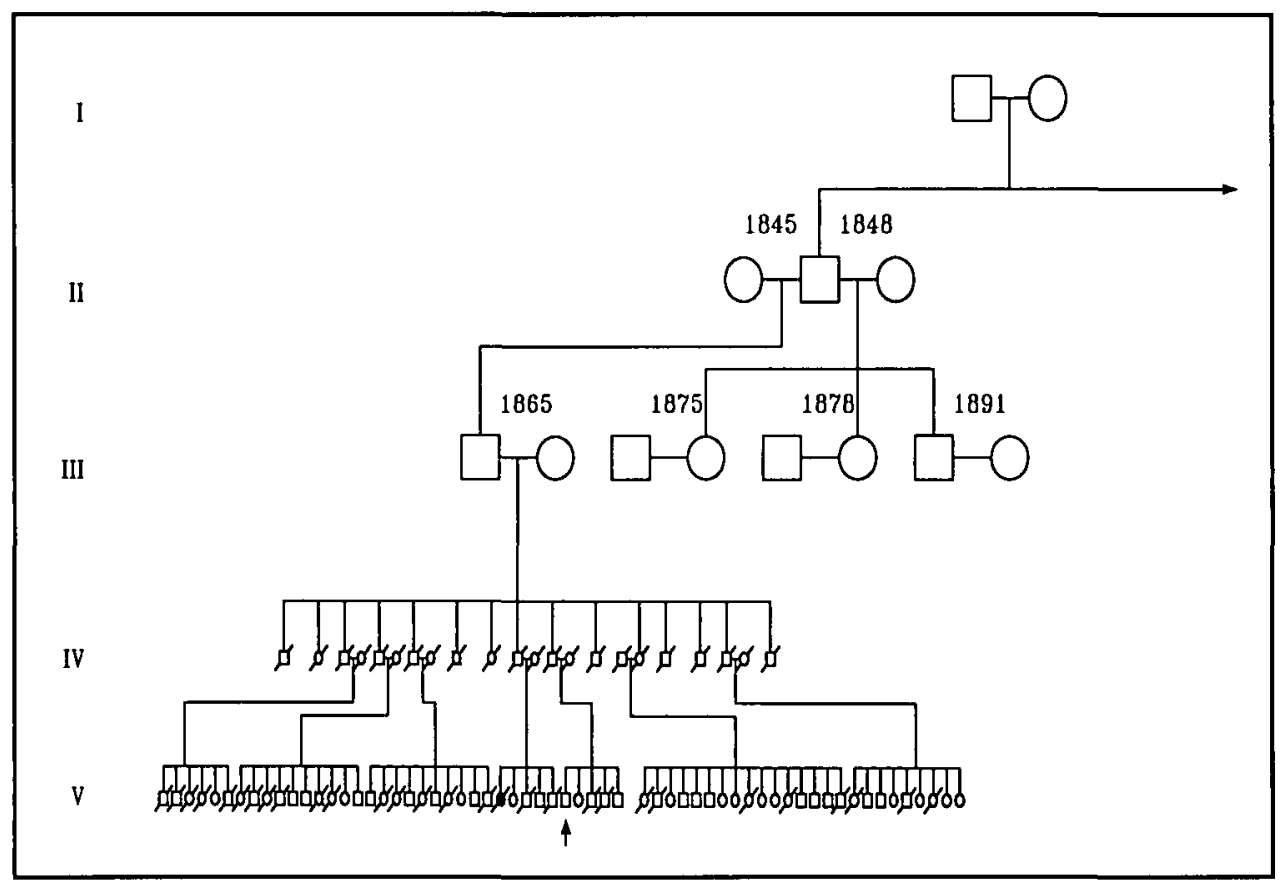

Figure 3 - Vertical expansion of pedigree IMAGE/l obtained through the SOREP data-base. The indicated dates represent the dates of marriage of the respective couples. 
beyond the age of 60,12 have been affected by cognitive deficits. The mean age of onset in this family is $69.7 \pm 8.0$ years.

We have assessed the informativeness of this pedigree for genetic linkage studies by performing computer simulations using the program SIMLINK. ${ }^{15}$ This program randomly assigns appropriate genotypes to all individuals available for sampling and then uses the LIPED program ${ }^{16.17}$ to calculate lod scores. This exercise enables the investigator to estimate the power afforded by a given family in subsequent analyses. The results of the simulated genotypic combinations (1000 replicates) are presented in Table 1. To date, in the literature, no single FAD family has given a lod score of 3 or more, ${ }^{18-22}$ the value required for demonstrating linkage. These results indicate that IMAGE/1 can be considered an informative family and that, with two or more such families, we should be able to establish or exclude linkage using di-allelic markers with a level of heterozygosity comparable to the one we used in the simulation (frequencies of $0.71 / 0.29$ in the general population). Hence, we have started to genotype members of this family for the markers on the long arm of chromosome 21 (D21S1/S11, D21S16) shown to be linked to the disease in early onset families. ${ }^{18-22}$

During the course of this work, we were also able to identify the great-grandparents and the great-great-grandparents of the proband through the resources available through SOREP (Figure 3). We are now in the process of finding the descendants of these couples in order to carry out family medical history investigations in these individuals. If we do find additional cases amongst the descendants, the ability to link together all these sibships will render the family IMAGE/l even more informative.

Based on an estimated collection of $500 \mathrm{AD}$ cases in the SLSJ area, even if only $5 \%$ of all cases are familial in nature and appropriate for linkage studies, we expect to be working from a base of 10 to 20 families. Given that the family structure described above is the norm rather than the exception in SLSJ, the population of the IMAGE registry provides a formidable resource to molecular genetics studies.

\section{ACKNOWLEDGEMENTS}

We would like to thank Louis Sénécal for the graphic design of Figures 2 and 3. This work was funded by the Medical Research Council, the Alzheimer Society of Canada, the Fondation de l'Age d'Or du Québec and the Fondation J.-Louis Lévesque.

\section{REFERENCES}

1. Akesson $H$. A population study of senile and arteriosclerotic psychoses. Hum Hered 1969; 19: 546-566.

2. Heston L, Mastri AR, Anderson E, et al. Dementia of the Alzheimer type: clinical genetics, natural history, and associated conditions. Arch Gen Psychiatry 1981; 38: 1085-1090.
3. Soinenen H, Heinonen OP. Clinical and etiological aspects of senile dementia. Eur Neurol 1982; 21: 401-410.

4. Heyman A, Wilkinson WE, Hurwitz BJ, et al. Alzheimer's disease: genetic aspects and associated clinical disorders. Ann Neurol $1983 ; 14: 507-515$.

5. Shalat SL, Seltzer B, Pidcock C, et al. Risk factors for Alzheimer's disease: a case-control study. Neurology 1987; 37: 1630-1633.

6. Fitch N, Becker R, Heller A. The inheritance of Alzheimer's disease: a new interpretation. Ann Neurol 1988; 23: 14-19.

7. Sulkava R, Haltia M, Paetau A, et al. Accuracy of clinical diagnosis in primary degenerative dementia: correlation with neuropathological findings. J Neurol Neurosurg Psychiatry 1983; 46: 9-13.

8. Wade JPH, Mirsen TR, Hachinski VC, et al. The clinical diagnosis of Alzheimer's disease. Arch Neurol 1987; 44: 24-29.

9. Gauvreau D, Bouchard R, Gauthier S, et al. The IMAGE Project: a geographical laboratory for the integration of multidisciplinary data. In: Sinet PM, Lamour Y, Christen Y. eds. Genetics and Alzheimer's disease. Heidelberg: Springer-Verlag, 1988: 40-50.

10. Gauvreau D, Bouchard R, Gauthier S, et al. The IMAGE Project: a multimatrix model for the study of Alzheimer disease. $\ln$ : Blass JP, Miner G, Miner LA, et al. eds. New York: Dekker, 1989: 331-365.

11. Bird TD, Lampe TH, Nemens EJ, et al. Familial Alzheimer's disease in American descendants of the Volga Germans: probable genetic founder effect. Ann Neurol 1988; 23: 25-31.

12. McKhann G, Drachman D, Folstein M, et al. Clinical diagnosis of Alzheimer's disease. Neurology 1984; 34: 939-944.

13. Khachaturian ZS. Diagnosis of Alzheimer's disease. Arch Neurol 1985; 42: 1097-1105.

14. Breitner JCS, Silverman JM, Mohs RC, et al. Familial aggregation in Alzheimer's disease: comparison of risk among relatives of early-and late-onset cases, and among male and female relatives in successive generations. Neurology 1988; 38: 207-212.

15. Boehnke M. Estimating the power of a proposed linkage study: a practical computer simulation approach. Am J Hum Genet 1986; 39: 513-527.

16. Ott J. Estimation of the recombination fraction in human pedigrees: efficient computation of the likelihood for human linkage studies. Am J Hum Genet 1974; 26: 588-597.

17. Ott $\mathbf{J}$. A computer program for linkage analysis of general human pedigrees. Am J Hum Genet 1976; 28: 528-529.

18. St. George-Hyslop PH, Tanzi RE, Polinsky RJ, et al. The genetic defect causing familial Alzheimer's disease maps on chromosome 21 . Science 1987; 235: 885-890.

19. Schellenberg GD, Bird TD, Wijsman EM, et al. Absence of linkage of chromosome $21 \mathrm{q} 21$ markers to familial Alzheimer's disease. Science 1988; 241: 1507-1510.

20. Van Broeckhoven C, Van Hul W, Backhovens P, et al. Genetic linkage analysis in two large Belgian Alzheimer families with chromosome 21 DNA markers. In: Sinet PM, Lamour Y, Christen Y. eds. Genetics and Alzheimer's disease. Heidelberg: SpringerVerlag, 1988: 124-129.

21. Pericak-Vance MA, Yamaoka LH, Haynes CS, et al. Genetic linkage studies in late-onset Alzheimer's disease families. In: Sinet PM, Lamour Y, Christen Y. eds. Genetics and Alzheimer's disease. Heidelberg: Springer-Verlag, 1988: 116-123.

22. Goate AM, Haynes AR, Owen MJ, et al. Predisposing locus for Alzheimer's disease on chromosome 21. Lancet 1989; 352-355. 